\title{
Do campo à escola: compra de alimentos da agricultura familiar pelo Programa Nacional de Alimentação Escolar em Territórios da Cidadania de Goiás
}

\author{
Veruska Prado Alexandre ${ }^{1}$, Luciana de Oliveira Froes Gomes ${ }^{2}$, Simoni Urbano da Silva ${ }^{3}$, Géssica Mércia \\ Almeida ${ }^{4}$, Karine Anusca Martins ${ }^{5}$, Estelamaris Tronco Monego ${ }^{6}$, Lucilene Maria de Sousa ${ }^{7}$ e Maria \\ Raquel Hidalgo Campos ${ }^{8}$
}

Este artigo relata resultados da promoção da compra da agricultura familiar (AF) pelo Programa Nacional de Alimentação Escolar (PNAE) em municípios goianos, descrevendo a adequação das ações frente a legislação, os desafios e as soluções para a execução do programa. O estudo de intervenção foi desenvolvido em cinco etapas, entre fevereiro de 2012 e outubro de 2013, em 25 municípios de dois territórios da cidadania de Goiás, com a participação de gestor do PNAE e da agricultura, conselheiros da alimentação escolar, nutricionistas e agricultores familiares. A coleta de dados foi realizada por meio de entrevistas, diários e memórias. Dados quantitativos foram expressos em frequência simples e os qualitativos por categorias temáticas. Os resultados revelaram maior relato de articulações com a AF por todos os atores sociais, do mapeamento da produção pelo gestor PNAE e nutricionista e inserção de alimentos da AF nos cardápios. Houve um aumento de $10 \%$ para $60 \%$ no número de municípios que adquiriram produtos da AF no Território do Vale do Paraná. O porcentual de compra mais frequente foi de 20 a $29 \%$ em ambos territórios. As reflexões finais abordam questões de ordem política, institucional e agrícola/agrária, bem como pontos centrais para a efetivação do PNAE.

Palavras chave: Alimentação Escolar; Agricultura Familiar; Política Pública; Desenvolvimento Local.

\section{From farm to school: food purchase from family farmers by National School Food Program in Goiás Territories of Citizenship}

This article presents the results of the National School Food Program (NSFP) purchasing food from Family Farmers (FF) in municipalities of Goiás, and describes how the actions were adapted to legislation, and the challenges and solutions found in executing the program. An intervention study was conducted in five phases between February 2012 and October 2013 in 25 municipalities in two territories in Goiás, with the participation

\footnotetext{
${ }^{1}$ Faculdade de Nutrição, Universidade Federal de Goiás (UFG). Doutoranda, Ciências Sociais em Desenvolvimento, Agricultura e Sociedade - Universidade Federal Rural do Rio de Janeiro. Endereço para correspondência: Faculdade de Nutrição, Universidade Federal de Goiás, Rua 227, s/n, Quadra 68, Setor Leste Universitário, Goiânia, Goiás. CEP: 74605-080. Telefone: +55 (62) 3209-6270. Fax: +55 (62) 3209-6273. E-mail: veruskaprado@ufg.br

${ }^{2}$ Nutricionista. Mestre em Ciência e Tecnologia de Alimentos - Universidade Federal de Goiás (UFG). E-mail: lu@froes.org

${ }^{3}$ Faculdade de Nutrição - Universidade Federal de Goiás (UFG).E-mail: simoni.urbano@gmail.com

${ }^{4}$ Faculdade de Nutrição - Universidade Federal de Goiás (UFG). Doutoranda em Nutrição Humana - Universidade de Brasília. E-mail: gessicamercia@gmail.com

${ }^{5}$ Faculdade de Nutrição - Universidade Federal de Goiás (UFG).E-mail: karine_anusca@ufg.br

${ }^{6}$ Faculdade de Nutrição - Universidade Federal de Goiás (UFG). E-mail: estelamaris@ufg.br

${ }^{7}$ Faculdade de Nutrição - Universidade Federal de Goiás (UFG).E-mail: lumasa@ufg.br

${ }^{8}$ Faculdade de Nutrição - Universidade Federal de Goiás (UFG). E-mail: raquelhidalgocampos@gmail.com
} 
of the NSFP coordinator, the secretary of agriculture, school food counselors, nutritionists, and FFs. Data were obtained through interviews, journals, and memories. Quantitative data were analyzed by simple frequency and the qualitative data by categories. The results revealed more articulations between FFs and all social actors, mapping of agricultural production by the NSFP coordinator and the nutritionist, and the inclusion of FF products in school menus. Food purchasing increased from $10 \%$ to $60 \%$ in the Vale do Parana territory. The most frequent purchasing percentage was 20 to $29 \%$ in both territories. The final reflections were categorized according to policy, institution, and agriculture/agrarian issues. This experience allowed us to identify central points for implementing the NSFP.

Keywords: School Feeding; Family Farming; Public Policy; Local Development.

\section{INTRODUÇÃO}

O Programa Nacional de Alimentação Escolar (PNAE) é o programa social do governo federal mais antigo na área da educação e o mais abrangente na área de alimentação escolar [1]. Com a publicação da Lei 11.947, em junho de 2009 [2], tornou-se um marco para as políticas públicas de Segurança Alimentar e Nutricional (SAN) tanto no Brasil quanto no mundo [3]. Um dos aspectos que contribuíram para este reconhecimento foi a inclusão de agricultores familiares como fornecedores de alimentos para o PNAE, promovendo potencialmente a SAN e o Direito Humano à Alimentação Adequada (DHAA) na comunidade escolar $[4,5]$.

O Artigo 14, da Lei no 11.947/2009 determina que "... do total dos recursos financeiros repassados pelo Fundo Nacional de Desenvolvimento da Educação (FNDE), no âmbito do PNAE, no minimo 30\% (trinta por cento) deverão ser utilizados na aquisição de gêneros alimentícios diretamente da agricultura familiar e do empreendedor familiar rural ou de suas organizaçoes...” "2]. Esta integração da agricultura familiar com a alimentação escolar promove aos estudantes o acesso a uma alimentação mais adequada, com cardápios diversificados, baseados em produtos alimentares locais e aos agricultores familiares um espaço para comercialização [6,7]. Reconhece-se ainda o potencial desta política pública em estimular o debate sobre soberania alimentar, SAN e modelos de produção de alimentos sustentáveis [7].

Neste sentido, o apoio à agricultura familiar representa $\mathrm{o}$ resgate do patrimônio alimentar, reintegrando as dimensões da produção e do consumo de alimentos, contribuindo para a redução da iniquidade, promovendo a geração de renda para os agricultores familiares e sinaliza uma relevante estratégia de redução da pobreza e do êxodo rural [8,9,10].
A gestão do PNAE pode contribuir com a economia local auxiliando os agricultores a se organizarem por meio de cooperativas ou associações; ofertando serviços de inspeção sanitária e organizando mercados atacadistas e centrais de abastecimento ou centrais de distribuição [11]. Outro aspecto destacado é que a valorização de alimentos regionais na elaboração dos cardápios, além de considerar a identidade cultural, pode levar ao uso sustentável dos biomas e a inserção de práticas alimentares mais saudáveis ${ }^{[12]}$.

Além disso, a formação de cadeias alimentares curtas que conectam os consumidores aos produtores por meio de mercados institucionais públicos, vem se constituindo em uma alternativa ao modelo dominante de abastecimento alimentar [13].

As cadeias produtivas curtas associadas às políticas de SAN podem contribuir para a superação da dicotomia campo, enquanto espaço de produção de alimentos, e cidade, como espaço de consumo [14].

O panorama da aquisição de gêneros alimentícios da agricultura familiar para o PNAE, embora sinalizando resultados promissores, ainda representa um desafio ${ }^{[10]}$.

Apesar da sua importância como estratégia de inclusão produtiva e de promoção da $\mathrm{SAN}$, a compra institucional pelo PNAE é marcada por dificuldades burocráticas, institucionais, políticas, econômicas e organizacionais que muitas vezes impedem a execução da lei [4,15]. Nessa perspectiva, a vontade política, as regras institucionais, o controle social e a intersetorialidade são pontos fundamentais para que o programa seja instrumento de desenvolvimento local e de promoção de hábitos alimentares adequados e saudáveis. 
As mudanças na legislação do PNAE são ainda consideradas recentes e análises sobre a compra de alimentos para a alimentação escolar são relevantes, considerando a necessidade de fortalecer a agricultura familiar e de estimular a utilização de alimentos regionais ${ }^{2,10]}$. Nesta perspectiva, o Centro Colaborador em Alimentação e Nutrição do Escolar, da Universidade Federal de Goiás (CECANE UFG), nos anos de 2012 e 2013, desenvolveu, em parceria com o FNDE, o projeto "Formação de atores sociais no âmbito do PNAE em Territórios da Cidadania no estado de Goiás", tendo como objetivo geral auxiliar na superação dos entraves e fortalecimento dos aspectos facilitadores na execução da Lei no 11.947/2009 [2]. Este projeto contou ainda com alguns objetivos específicos dentre os quais: identificar sujeitos estratégicos individuais, coletivos e institucionais envolvidos no processo de inclusão de produtos da agricultura familiar na alimentação escolar; mapear processos e mediações entre a produção de alimentos até a oferta na alimentação escolar; identificar estratégias para o enfrentamento de entraves e fortalecimento de aspectos facilitadores na execução da Lei no 11.947/2009; sensibilizar os diferentes sujeitos estratégicos envolvidos com a alimentação escolar sobre a promoção de práticas alimentares saudáveis, com ênfase na inserção de alimentos locais; formar agricultores familiares e outros sujeitos estratégicos em temas relacionados ao PNAE; e apoiar os agricultores familiares dos Territórios da Cidadania para a produção de alimentos com uso potencial pelo PNAE.

Este artigo relata os resultados decorrentes da atuação da equipe do CECANE UFG na promoção da compra da agricultura familiar pelo PNAE em municípios que compõem dois territórios da cidadania em Goiás, descrevendo a adequação das ações perante a legislação do programa, os desafios e as soluções encontradas para a sua execução.

\section{METODOLOGIA}

O estudo de intervenção foi desenvolvido entre fevereiro de 2012 e outubro de 2013, em 15 municípios do Território da Cidadania do Vale do Rio Vermelho (TVRV) e em 10 do Território da Cidadania do Vale do Paranã (TVP), ambos no estado de Goiás.
Os territórios da cidadania abrangem os municípios de mais baixo Índice de Desenvolvimento Humano (IDH) do país, com vistas a implantar políticas públicas integradas para a promoção da equidade e superação da fome e da pobreza [1]. No período da execução do projeto, existiam quatro territórios da cidadania no estado de Goiás, dos quais foram escolhidos os dois com maior número de municípios e de agricultores assentados.

O trabalho de campo foi realizado por duplas formadas por nutricionista e engenheiro agrônomo ou administrador com formação na temática da agricultura familiar. As ações de promoção da compra da agricultura familiar pela alimentação escolar foram desenvolvidas predominantemente no âmbito da gestão municipal, sendo apenas os momentos de formações realizados de forma a integrar os municípios do TVRV e TVP.

Ressalta-se que as atividades do projeto foram apoiadas na descrição da Lei no 11.947/2009 [2] e Resolução CD/FNDE no 38/2009 [17], esta última vigente à época. A título de atualização e sempre que pertinente, resoluções posteriores, como a Resolução CD/FNDE no 26/2013 [18] e a Resolução CD/FNDE no 4/2015 [19], serão referidas.

Em relação aos atores sociais participantes do projeto citam-se: gestor(a) do PNAE, gestor(a) da agricultura (ou órgão municipal responsável pelo setor), conselheiros(as) da alimentação escolar, nutricionista (responsável técnico e quadro técnico) e agricultores(as) familiares. Em relação a estes últimos, foram contemplados não somente aqueles organizados em cooperativas ou associações, como também os não inseridos nestas organizações.

A execução do projeto ocorreu em cinco etapas, conforme sistematizado na Figura 1. 
Figura 1. Fluxograma das etapas do projeto "Formação de atores sociais no âmbito do PNAE em Territórios da Cidadania no estado de Goiás". Goiás, 2013

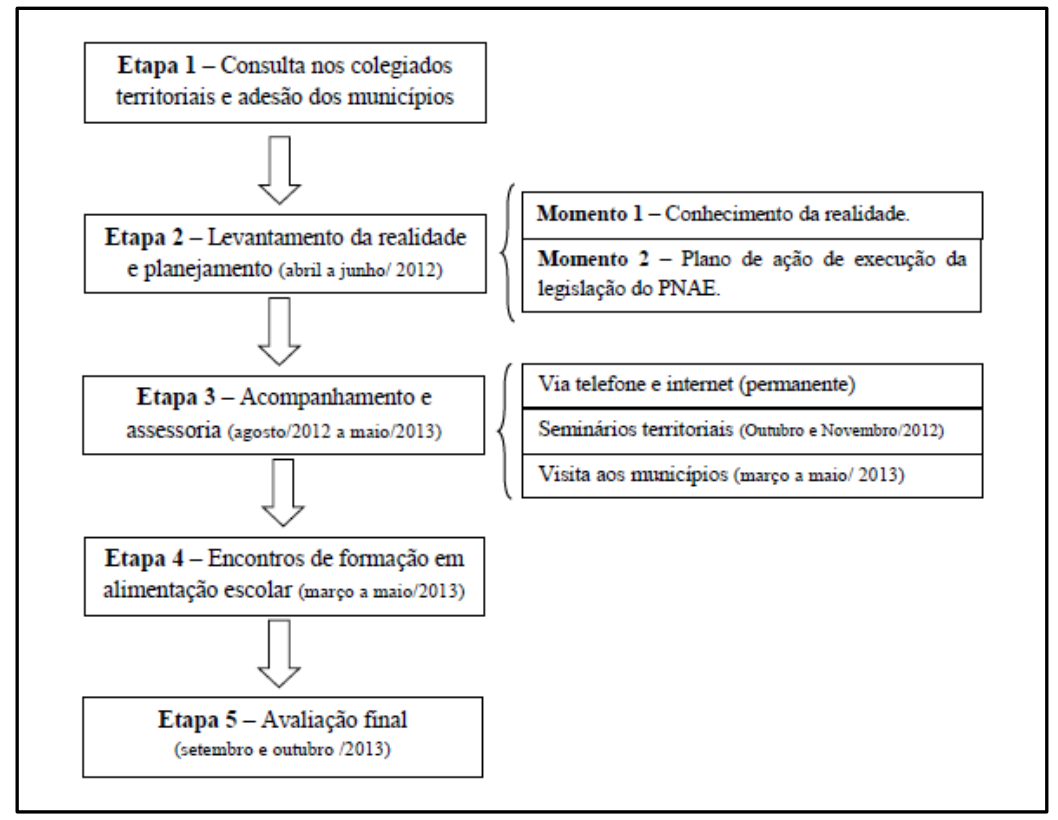

A primeira etapa (E1) foi realizada em fevereiro de 2012, com a apresentação da proposta aos membros dos colegiados territoriais do TRV e TVP, com vistas a buscar a adesão dos municípios, adequar o projeto as demandas da região e aprovar a execução deste. A segunda etapa (E2), realizada entre abril a junho de 2012, compreendeu o levantamento da realidade local/regional e o planejamento participativo das ações por município. A E2 foi realizada em dois momentos, sendo o primeiro concentrado na execução do PNAE, com ênfase no processo de compra de alimentos da agricultura familiar. Foram realizadas entrevistas com gestor(a) do PNAE, gestor(a) da agricultura, conselheiros(as) da alimentação escolar e nutricionista, utilizando um roteiro semiestruturado construído a partir das orientações da Resolução CD/FNDE no 38/2009 [17]. Todos os atores sociais participantes desta etapa responderam à pergunta sobre a realização de ações integradas entre os setores da alimentação escolar e da agricultura familiar no município, além de questões diferenciadas segundo as responsabilidades descritas na legislação do PNAE.

Assim, ao gestor (a) do PNAE foi perguntado sobre o conhecimento da legislação, realização do mapeamento dos alimentos produzidos pela agricultura familiar no município ou região e apoio no processo de entrega de alimentos adquiridos da agricultura familiar. O gestor responsável pela agricultura familiar foi questionado sobre o conhecimento da legislação, o procedimento da chamada pública de compra e a oferta de Assistência Técnica e Extensão Rural (ATER). Ao nutricionista questionou-se a realização de mapeamento da produção e a inclusão de produtos da agricultura familiar nos cardápios escolares. $\mathrm{O}$ conselheiro de alimentação escolar respondeu sobre acompanhamento da execução do PNAE e presença de representantes da agricultura familiar no Conselho de Alimentação Escolar (CAE). Este roteiro foi aplicado aos mesmos atores sociais ao final do projeto (Etapa 5), como uma forma de avaliação.

O segundo momento da E2 teve como enfoque a construção de um plano de ação municipal para a efetivação do Artigo 14, da Lei no 11.947/2009 [2]. Este planejamento foi realizado por meio de uma oficina com metodologia de rodas de conversa, trabalhos em grupo e debates em plenária, tendo como referencial a educação popular [20]. Participaram os atores descritos no momento um da E2 e também agricultores familiares, representantes do setor de compras da prefeitura e técnicos locais da Emater 
Goiás. O debate foi orientado pelo "Passo a passo para compra/venda de alimentos da agricultura familiar para a alimentação escolar" [21], levantando entraves para a execução do PNAE e estratégias de superação, identificando parceiros à execução do PNAE no município e pontos fortes da gestão municipal, os quais foram trabalhados visando o seu fortalecimento. $\mathrm{O}$ planejamento contemplou a identificação de ações, estabelecimento de responsáveis e prazos de execução.

A terceira etapa (E3) ocorreu entre agosto de 2012 a maio de 2013 compreendendo o acompanhamento da execução dos planos de ação municipais. A equipe do CECANE UFG prestou assessoria aos municípios por meio de três estratégias: 1) Acompanhamento via telefone e internet; 2) Realização de seminários nos territórios; e 3) Visita aos municípios. Outra estratégia adotada foi a realização de um seminário em cada território, nove meses após o início do projeto, visando dialogar refletir sobre resultados parciais, propor alterações e revisões nos planos de ação municipais. Por fim, um ano após o início do projeto, realizaram-se visitas aos municípios para assessoria técnica sobre a compra da agricultura familiar in loco e levantamento de temas de interesse para os encontros de formação em alimentação escolar.

A etapa quatro (E4) foi composta por encontros de formação sobre os temas antes referidos, planejados em parceria com os atores sociais dos municípios e com os membros dos colegiados territoriais. A quinta e última etapa (E5) consistiu na realização de um seminário de avaliação e encerramento do projeto. Nas etapas 4 e 5 , as ações foram organizadas no âmbito da articulação territorial (TVRV ou TVP) buscando integrar em um mesmo espaço todos os municípios participantes do projeto.
A equipe executora do projeto registrou todo o processo em diários de campo e memórias de encontros/reuniões/seminários, os quais constituíram as fontes da análise qualitativa das ações do projeto com foco nas categorias temáticas dos entraves e estratégias adotadas para sua superação [22]. De forma complementar, a equipe do CECANE UFG analisou as chamadas públicas divulgadas nos anos de 2012 e 2013avaliando a conformidade destas à Resolução CD/FNDE oㅡ 38/2009 [17].

Os dados quantitativos obtidos por meio dos questionários foram tabulados no programa Excel 2010. A análise descritiva foi determinada por meio de frequência simples, referente aos momentos inicial e final da intervenção.

Este projeto foi analisado e aprovado pelo Comitê de Ética em Pesquisa da Universidade Federal de Goiás, sob o protocolo 055/09.

\section{RESULTADOS E DISCUSSÃO}

Participaram deste estudo 25 municípios, dos quais 15 do TVRV e 10 do TVP. O projeto atuou em $94 \%$ ( $\mathrm{n}=15)$ municípios do TVRV, que é composto por 16 cidades e em $83 \%(\mathrm{n}=10)$ dos municípios que compõe o TVP (Total=12). As perdas representam municípios com pendências junto ao FNDE, levando ao não recebimento dos recursos do PNAE em 2012 $(8 \%, n=2)$ e por recusa do gestor municipal $(4 \%, n=1)$. As características dos municípios participantes estão descritas da Tabela 1. O TVRV contava com 7.287 agricultores familiares e o TVP com 5.787; na ocasião, eram os dois territórios com o maior número de famílias assentadas do estado de Goiás, de 1.080 e 3.389, respectivamente [23]. 
Tabela 1. Caracterização dos municípios quanto à população total, população rural, Declaração de Aptidão ao PRONAF (DAP), recurso destinado para a alimentação escolar, Indice de Desenvolvimento da Educação Básica (IDEB) e Índice de Desenvolvimento Humano (IDH)

\begin{tabular}{|c|c|c|c|c|c|c|c|}
\hline \multirow{2}{*}{ Município } & \multirow{2}{*}{$\begin{array}{l}\text { População } \\
\text { total }^{1}\end{array}$} & \multirow{2}{*}{$\begin{array}{l}\text { População } \\
\text { rural }^{1}\end{array}$} & \multirow{2}{*}{$\begin{array}{l}\text { DAP's } \\
\text { ativa }^{2}\end{array}$} & \multirow{2}{*}{$\begin{array}{c}\text { Recurso } \\
\text { PNAE }(\mathrm{R} \$)^{3}\end{array}$} & \multicolumn{2}{|c|}{ IDEB $^{4}$} & \multirow{2}{*}{$\mathrm{IDH}^{1}$} \\
\hline & & & & & 4o e 5o & 8o e 9 은 & \\
\hline Buriti de Goiás & 2.560 & 825 & 177 & 14.520 & 6,1 & 4,2 & 0,731 \\
\hline Carmo do Rio Verde & 8.928 & 1.874 & 261 & 62.100 & 5,2 & 4,0 & 0,728 \\
\hline Córrego do Ouro & 2.632 & 999 & 210 & 20.520 & 5,2 & 4,9 & 0,726 \\
\hline Goiás & 24.727 & 6.089 & 513 & 105.660 & 5,6 & 4,4 & 0,736 \\
\hline Guaraíta & 2.376 & 934 & 269 & 25.200 & 5,3 & 4,1 & 0,697 \\
\hline Heitoraí & 3.571 & 926 & 152 & 17.220 & 5,8 & 3,3 & 0,744 \\
\hline Itaberaí & 35.371 & 5.587 & 588 & 286.620 & 5,9 & 4,7 & 0,739 \\
\hline Itaguari & 4.513 & 545 & 222 & 34.680 & 6,2 & 4,8 & 0,720 \\
\hline Itaguaru & 5.437 & 916 & 362 & 27.300 & 5,0 & 5,0 & 0,746 \\
\hline Itapirapuã & 7.835 & 2.299 & 371 & 43.980 & 4,9 & 4,0 & 0,707 \\
\hline Itapuranga & 26.125 & 4.890 & 1.074 & 138.660 & 5,6 & 4,7 & 0,735 \\
\hline Morro Agudo de Goiás & 2.356 & 707 & 142 & 12.480 & 4,4 & 4,2 & 0,717 \\
\hline Mossâmedes & 5.007 & 1.732 & 215 & 27.000 & 5,7 & 5,3 & 0,750 \\
\hline Sanclerlândia & 7.550 & 1.482 & 199 & 37.400 & 6,2 & 5,0 & 0,734 \\
\hline Taquaral de Goiás & 3.541 & 660 & 156 & 25.080 & 5,1 & 4,1 & 0,726 \\
\hline Uruana & 13.826 & 2.594 & 450 & 62.160 & 5,4 & 3,5 & 0,758 \\
\hline Total TVRV & 156.355 & 33.059 & 5.361 & 940.580 & - & - & 0,740 \\
\hline Alvorada do Norte & 8.084 & 1.211 & 16 & 94.620 & 4,9 & 3,7 & 0,688 \\
\hline Buritinópolis & 3.321 & 1.436 & 46 & 33.840 & 4,6 & 4,0 & 0,600 \\
\hline Damianópolis & 3.292 & 1.439 & 78 & 14.340 & 4,7 & 4,0 & 0,634 \\
\hline Divinópolis de Goiás & 4.962 & 1.471 & 63 & 24.300 & 4,5 & 4,0 & 0,675 \\
\hline Flores de Goiás & 12.066 & 8.896 & 273 & 126.720 & 4,2 & 4,0 & 0,642 \\
\hline Guarani de Goiás & 4.258 & 2.495 & 90 & 36.480 & 4,5 & 4,2 & 0,632 \\
\hline Iaciara & 12.427 & 3.127 & 28 & 120.480 & 4,7 & 4,1 & 0,704 \\
\hline Mambaí & 6.871 & 2.069 & 36 & 54.180 & 4,6 & 3,9 & 0,647 \\
\hline Posse & 31.419 & 7.480 & 297 & 278.220 & 5,7 & 4,3 & 0,711 \\
\hline São Domingos & 11.272 & 5.498 & 114 & 82.980 & 5,3 & 4,3 & 0,631 \\
\hline Simolândia & 6.514 & 1.136 & 24 & 49.380 & 4,8 & 4,3 & 0,657 \\
\hline Sítio D`Abadia & 2.825 & 1.831 & 142 & 1.758 & 5,0 & 4,2 & 0,643 \\
\hline Total TVP & 107.311 & 38.089 & 1.207 & 917.298 & - & - & 0,670 \\
\hline Estado de Goiás & 6.003 .788 & 583.074 & * & 87.813 .900 & 5,1 & 3,9 & 0,735 \\
\hline
\end{tabular}

TVRV - Território da Cidadania Vale do Rio Vermelho

TVP - Território da Cidadania Vale do Paranã

Fontes: ${ }^{1}$ IBGE [24]; ${ }^{2}$ Brasil [23]; ${ }^{3}$ Brasil [25]; ${ }^{4}$ INEP [26]

*Fonte fornece valores por município 
Todos os gestores do PNAE relataram conhecer a legislação no início e final do projeto (Tabela 2). A frequência de gestores que consideram como função da Secretaria de Educação a realização do mapeamento da produção local e a realização de ações integradas entre alimentação escolar e a agricultura familiar foi maior ao final do projeto (Tabela 2).

A realização de ações integradas entre o setor educação e a agricultura familiar foi maior após as intervenções realizadas, principalmente no TVP (Tabela 2). Bezerra et al. [27] e Carvalho ${ }^{[28]}$ afirmam o comprometimento dos gestores como uma das condições indispensáveis para o êxito de políticas públicas, como a Lei no11.947/2009. A honestidade, compromisso e vontade política expressos em editais coerentes é fundamental para este processo [28]. É importante ressaltar o apoio se inicia quando o gestor conhece a realidade dos agricultores familiares, podendo a partir desta apropriação planejar melhor o processo de compra, de acordo com a sazonalidade e também a vocação produtiva ${ }^{[10]}$.

Quando indagados sobre a presença de algum tipo de suporte ao processo de entrega de produtos da agricultura familiar nas escolas, menos de $25 \%$ dos gestores municipais do PNAE relataram apoiar, no início e ao final do projeto. Esta não é de fato uma atribuição determinada pela legislação do PNAE à educação, no entanto, reconhece-se que o apoio logístico, principalmente quando no início do processo pode ser central para o alcance dos, pelo menos, 30\% exigidos por lei.

Com relação aos gestores municipais da agricultura, 60,0\% em ambos os territórios alegaram conhecer a legislação no início do projeto, proporção que diminuiu ao final do estudo (Tabela 2). Este resultado pode ser parcialmente explicado pela descontinuidade administrativa decorrente do processo de eleições municipais em 2012. Outros elementos foram analisados a partir deste ator social (Tabela 2), sendo observado um aumento, ao final do projeto, no relato de uma maior integração entre a gestão municipal da agricultura e grupos de agricultores familiares. Em relação ao conhecimento sobre a chamada pública e também sobre a existência de ATER municipal voltada para a agricultura familiar foram observadas reduções na frequência relatada pelos gestores da agricultura entrevistados. Vale destacar que no início do projeto foi frequente na fala dos gestores da agricultura a identificação de ATER como oferta de serviços com maquinários (niveladoras e retroescavadeiras) doados pelo Ministério do Desenvolvimento Agrário. A equipe do projeto buscou sensibilizar os gestores deste setor quanto aos demais elementos que compõem uma ATER, ação que pode ter influenciado na redução do número de respostas positivas quanto à oferta de ATER ao final do projeto. 
Tabela 2. Informações sobre a implementação da compra da agricultura familiar para a alimentação escolar, antes e após a intervenção. Goiás, 2013

\begin{tabular}{|c|c|c|c|c|c|c|}
\hline \multirow{2}{*}{ Variáveis } & \multicolumn{2}{|c|}{ TVRV $(n=15)$} & \multicolumn{2}{|c|}{$\operatorname{TVP}(\mathrm{n}=10)$} & \multicolumn{2}{|c|}{ Total $(n=25)$} \\
\hline & $\begin{array}{c}2012 \\
(\%) \\
\end{array}$ & $\begin{array}{c}2013 \\
(\%) \\
\end{array}$ & $\begin{array}{c}2012 \\
(\%) \\
\end{array}$ & $\begin{array}{c}2013 \\
(\%) \\
\end{array}$ & $\begin{array}{c}2012 \\
(\%) \\
\end{array}$ & $\begin{array}{c}2013 \\
(\%)\end{array}$ \\
\hline \multicolumn{7}{|c|}{ Gestão municipal do PNAE (Secretaria de Educação) } \\
\hline Conhece legislação & 100,0 & 100,0 & 100,0 & 100,0 & 100,0 & 100,0 \\
\hline Realiza mapeamento da produção & 80,0 & 80,0 & 40,0 & 60,0 & 64,0 & 72,0 \\
\hline Articula com AF & 86,7 & 100,0 & 50,0 & 100,0 & 72,0 & 100,0 \\
\hline Apoia processo de entrega da AF & 13,4 & 20,0 & 20,0 & 30,0 & 16,0 & 24,0 \\
\hline \multicolumn{7}{|c|}{ Gestão municipal da agricultura $^{1}$} \\
\hline Conhece legislação PNAE & 60,0 & 53,4 & 60,0 & 40,0 & 60,0 & 48,0 \\
\hline Articula com AF & 46,7 & 66,7 & 30,0 & 50,0 & 40,0 & 60,0 \\
\hline Conhece CP & 53,4 & 46,7 & 40,0 & 40,0 & 48,0 & 44,0 \\
\hline Oferta ATER para AF & 66,7 & 66,7 & 70,0 & 40,0 & 68,0 & 56,0 \\
\hline \multicolumn{7}{|c|}{ Nutricionista $^{2}$} \\
\hline Realiza mapeamento da produção & 53,5 & 93,3 & 60,0 & 92,0 & 56,0 & 92,0 \\
\hline Cardápio com produtos da $\mathrm{AF}$ & 93,4 & 100,0 & 60,0 & 90,0 & 80,0 & 96,0 \\
\hline Articula com AF & 46,7 & 73,4 & 20,0 & 50,0 & 36,0 & 64,0 \\
\hline \multicolumn{7}{|c|}{ Conselho de Alimentação Escolar } \\
\hline \multirow{3}{*}{$\begin{array}{l}\text { Acompanha execução da Lei } \\
\text { Tem AF no CAE } \\
\text { Articula com AF }\end{array}$} & 66,7 & 80,0 & 60,0 & 70,0 & 64,0 & 76,0 \\
\hline & 13,3 & 26,7 & 40,0 & 10,0 & 24,0 & 20,0 \\
\hline & 53,3 & 46,7 & 30,0 & 60,0 & 44,0 & 52,0 \\
\hline \multicolumn{7}{|c|}{$\begin{array}{l}\text { TVRV - Território da Cidadania Vale do Rio Vermelho } \\
\text { TVP - Território da Cidadania Vale do Paranã } \\
\text { PNAE - Programa Nacional de Alimentação Escolar } \\
\text { AF - Agricultor(a) Familiar } \\
\text { CP - Chamada Pública } \\
\text { ATER - Assistência Técnica e Extensão Rural } \\
\text { 'TVRV: dos } 15 \text { municípios participantes, somente } 10 \text { e } 12 \text { gestores municipais da agricultura responderam o questionário em } 2012 \text { e 2013, respectivamente. TVP: dos } 10 \text { município } \\
\text { participantes, apenas } 7 \text { gestores municipais da agricultura responderam ao questionário } \\
\text { 'Dos } 10 \text { municípios participantes no TVP, apenas } 7 \text { nutricionistas responderam o questionário em } 2012 \text { e } 9 \mathrm{em} 2013\end{array}$} \\
\hline
\end{tabular}

Em relação ao nutricionista, o relato de realização ou acompanhamento do processo de mapeamento de produtos da agricultura familiar disponíveis no município, inserção de alimentos da agricultura familiar nos cardápios ou ainda a maior aproximação com a agricultura familiar, apresentaram maiores frequências ao final do projeto, em comparação ao seu início, com destaque para o TVP (Tabela 2). Ressalta-se também que a inserção dos produtos da agricultura familiar nos cardápios é fundamental para que, no médio e longo prazos, os agricultores familiares planejem a produção dos alimentos, podendo com isso responder à demanda $\mathrm{e}$ garantir a oferta permanente de produtos ${ }^{[10]}$.

Desta forma, reforça-se o papel fundamental desempenhado pelo(a) nutricionista no processo de execução do PNAE, principalmente quanto ao processo de aquisição dos produtos da agricultura familiar, fato citado em outros estudos que apontaram a ausência do nutricionista como uma das principais dificuldades enfrentadas na execução desta política pública [9,11,29]. Isso se deve à responsabilidade do nutricionista na elaboração do cardápio escolar [30], o que implica necessariamente no conhecimento da produção local, para na sequência planejar cardápios que contemplem estes produtos e considerem a promoção da alimentação saudável e da saúde associados ao aspecto da sustentabilidade ambiental, cultural, econômica e/ ou social [10].

Por fim, em relação ao CAE, pode-se observar uma menor presença de agricultores ao final do projeto (Tabela 2). O acompanhamento do cumprimento do Artigo 14 da Lei no 11.947/2009 pelo CAE obteve um discreto aumento na frequência entre 2012 e 2013. Esta atuação do CAE é especialmente importante para o cumprimento da legislação [15,27]. Entretanto, resultados 
encontrados por Saraiva et al. ${ }^{[10]}$ reforçam que há necessidade de fortalecer e implementar estratégias em diferentes setores públicos e da sociedade civil organizada, para se colocar em prática a compra de alimentos provenientes da agricultura familiar. Quanto à articulação do CAE com os agricultores familiares, a redução desta frequência no TVRV pode ser explicada pela renovação de alguns Conselhos em 2013, não havendo um tempo para que os novos conselheiros realizassem todas as atribuições descritas na Resolução CD/FNDE ำ 38/2009 [17].

Os resultados obtidos neste estudo corroboram com a análise feita por Saraiva et al. ${ }^{10]}$. Os autores afirmam a importância de uma atuação interdependente de diversas instâncias do poder executivo relacionadas ao tema da alimentação escolar, como agricultura, educação, administração, dentre outras, potencializando o desenvolvimento local por meio de uma ação setorial transversal. Esta atuação integrada voltada à efetivação de políticas públicas, destacada também por Triches, Gerhardt e Schneider [31], contribuiria para a superação de desafios diversos vivenciados na prática cotidiana de execução desta política pública de alimentação escolar.

Quanto à efetivação da compra da agricultura familiar pela alimentação escolar, no início do projeto, em 2012, 56\% ( $\mathrm{n}=11)$ dos municípios relataram realizar, sendo que ao final, em 2013, este percentual subiu para $80 \%(n=20)$. Daqueles que não compraram da agricultura familiar em 2012, 8\% ( $\mathrm{n}=2)$ alegaram não ter publicado uma chamada pública e $36 \%(\mathrm{n}=9)$ publicaram, porém não conseguiram efetivar a aquisição por ausência de propostas da agricultura familiar. No ano de 2013, o percentual de municípios que não lançaram a chamada permaneceu igual, porém houve redução na frequência daqueles que alegaram publicar a chamada sem receber nenhuma proposta dos agricultores $(12 \%, \mathrm{n}=3)$. Os principais motivos apontados para a ausência de entrega de propostas pelos agricultores foram a falta de documentação dos agricultores familiares para atender à chamada pública, o preço previsto para a compra, considerado baixo por alguns produtores e ainda a interpretação de que deveriam produzir e entregar exatamente todos os itens solicitados sem margem de negociação.

Ao avaliar os percentuais de compra efetuados pelos municípios (Figura 2), observa-se que no início, do total de municípios participantes no TVRV, 13,3\% $(\mathrm{n}=2)$ relataram não comprar da agricultura familiar.
Dos $86,7 \%(n=13)$ que compraram, a porcentagem mais frequente de compra foi maior ou igual a $30 \%$ do recurso enviado pelo FNDE. Esta predominância foi mantida ao final do projeto (Figura 2). Já no TVP, do total de municípios integrantes deste território apenas um $(10,0 \%)$ relatou cumprir a determinação de compra da agricultura familiar pela alimentação escolar em 2012, utilizando entre $20 \%$ a $29 \%$ do recurso. Ao final do projeto, foram identificados $60 \%$ dos municípios $(\mathrm{n}=6)$ comprando de agricultores familiares ou de suas organizações, sendo a faixa de porcentagem mais frequente mantida (Figura 2).

Os dados apresentados sobre compra da agricultura familiar pelo PNAE parecem indicar que a atuação pautada em princípios como a articulação intersetorial e atividades baseadas na realidade local desenvolvidas pela equipe do CECANE UFG, geraram bons resultados quanto ao alcance dos objetivos do PNAE. Embora a maioria dos municípios $(76 \%, \mathrm{n}=19$, do total de municípios no início do projeto e $68 \%$, $\mathrm{n}=17$, ao final) não tenham atingido o mínimo de $30 \%$ do recurso financeiro do PNAE destinado à compra da agricultura familiar ao final da intervenção, houve aumento nos percentuais de compras executadas. Os resultados de efetivação da compra neste projeto mostraram-se mais positivos do que aqueles encontrados por Bezerra et al. [27], o que pode estar associado ao fato de que neste estudo o tempo de atuação junto aos municípios ter sido maior.

Figura 2. Informações sobre a compra da agricultura familiar pela alimentação escolar em municípios de dois Territórios da Cidadania do estado de Goiás, 2012/2013

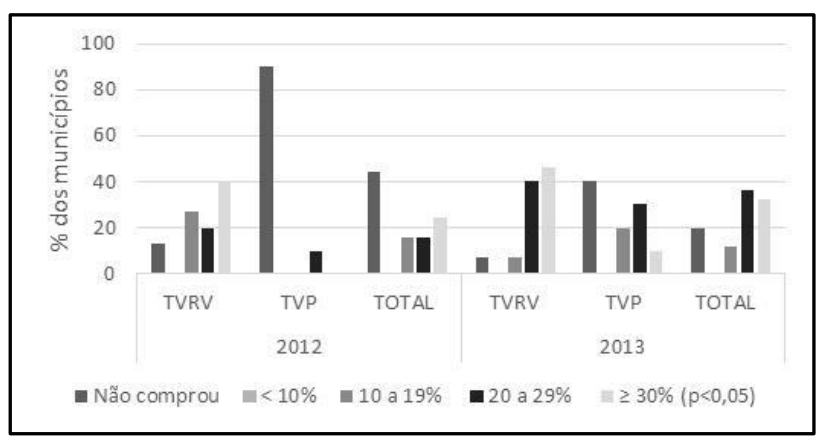

TVRV - Território da Cidadania Vale do Rio Vermelho TVP - Território da Cidadania Vale do Paranã 
Uma das alterações apresentadas na Resolução CD/FNDE no 26/2013, e mantida pela Resolução CD/FNDE no 4/2015, foi o estabelecimento de critérios para a escolha do projeto de venda incluindo a preferência por grupos formais, ao invés de grupos informais ou fornecedores individuais [18,19]. Esta recomendação fortalece a organização dos agricultores familiares em grupos formais (principalmente cooperativas) e facilita o acesso às chamadas públicas e aos mercados institucionais [32]. Os resultados deste projeto confirmam isso, uma vez que no TVRV a presença de associações e cooperativas em 2012 era de $66,7 \%$ e $46,7 \%$, respectivamente, enquanto no TVP era de $50,0 \%$ de associações e $20,0 \%$ de cooperativas.

É importante destacar que ações de incentivo podem promover melhoras no processo de aquisição da agricultura familiar pela alimentação escolar, como observado pelo aumento no percentual de municípios que compram da agricultura familiar, de 56\% (2012) para $80 \%$ (2013). Vale ressaltar também, que esta porcentagem é maior do que a média dos municípios que adquirem alimentos da agricultura familiar para o PNAE da região Centro-Oeste $(35,3 \%)$, e ainda superior à média nacional, que era de 47,4\% ${ }^{[10]}$.

Outros resultados deste estudo incluem o levantamento dos temas para os encontros de formação em alimentação escolar realizados na etapa 4, entre os meses de março a maio de 2013. Estes temas foram definidos pelos atores sociais dos municípios e elencados como estratégicos para a ampliação do processo de compra da agricultura familiar, sendo debatidos em três seminários sobre: (1) Inspeção sanitária de alimentos; (2) Regularização ambiental, sanitária e tributária; (3) Processo de compra da agricultura familiar pelo PNAE. Este último foi solicitado devido às mudanças na gestão municipal após as eleições em 2012.

Partindo da sistematização e análise de diários de campo, memórias de reuniões e encontros realizados ao longo do projeto foram elencados os principais entraves vivenciados nesta experiência, assim como as estratégias de superação adotadas para estes. Estes resultados são apresentados na próxima seção.

\section{Do campo à escola: reflexões sobre entraves e soluções}

$\mathrm{Na}$ execução do PNAE a articulação das instituições locais é determinante para o processo de compra da agricultura familiar. A clareza quanto a responsabilidades de cada ator neste processo pode diminuir os entraves da comercialização [15]. Neste estudo as reflexões sobre a execução do PNAE foram categorizadas em questão política, institucional e agrícola/agrária. Entende-se como questão agrícola aquelas vinculadas à produção (o que, quando e onde produzir), enquanto que a questão agrária faz referência a forma como esta ocorrerá [33].

\section{Reflexões sob a ótica política}

\section{O descumprimento do papel dos tomadores de decisão}

Nos municípios que não efetuaram a compra da agricultura familiar, verificou-se uma resistência por parte da gestão em cumprir sua atribuição de estimular e orientar os agricultores familiares quanto à comercialização para o PNAE. A execução deste projeto mostrou que a aproximação por meio de reuniões presenciais entre agricultores familiares com a gestão municipal do PNAE permitiu superar este entrave. Em alguns municípios do TVRV foi adotada a estratégia de orientar os agricultores ou seus representantes de forma contínua, com vistas a esclarecer dúvidas sobre o processo de compra.

A atuação política dos gestores municipais em prol da execução do PNAE corrobora com dados descritos por Triches e Schneider [9] a partir da percepção dos técnicos da Emater de um município do Rio Grande do Sul. No caso do PNAE a atuação deste ator torna-se imprescindível no processo de aproximação entre agricultores familiares e $\mathrm{O}$ consumidor (escolares), por meio da compra institucional [34,35]. 


\section{As condições de atuação do nutricionista}

O nutricionista é o responsável técnico pela execução do PNAE [18,30], devendo planejar, elaborar, acompanhar e avaliar o cardápio da alimentação escolar e interagir com os agricultores familiares e empreendedores familiares rurais e suas organizações [30].

No entanto, existe um franco processo de precarização desse profissional, traduzido em pouca valorização deste por parte da gestão municipal, expressa pela relação trabalhista via contratos temporários e com baixa carga horária, associado a reduzidos salários. Na maioria dos municípios visitados o nutricionista não elabora o planejamento anual e não cumpre com grande parte das atribuições previstas na Resolução CFN no 465/2010 [30], alegando desconhecimento da legislação ou falta de tempo hábil. As ações relatadas com maior frequência foram diagnosticar e realizar o acompanhamento nutricional dos escolares, e planejar, acompanhar e avaliar os cardápios. Esta realidade reflete na pouca articulação entre nutricionistas e agricultores e, consequentemente, na elaboração de cardápios que não privilegiam alimentos produzidos pela agricultura familiar local, um fator determinante para o êxito desta política [15].

No presente estudo, os gestores da educação foram esclarecidos quanto às atribuições dos nutricionistas, e estes, por sua vez, foram orientados sobre sua atuação no PNAE.

\section{Reflexões sob a ótica institucional}

\section{Inadequação das estruturas das unidades de alimentação e nutrição escolares (UAN escolar)}

A falta de infraestrutura adequada nas Unidades de Alimentação e Nutrição (UAN) das escolas para armazenar, preparar ou servir os alimentos foi citada como uma justificativa para a não realização da compra da agricultura familiar. As condições das UAN devem ser avaliadas pelo nutricionista em parceria com a Vigilância Sanitária municipal, a quem cabe elaborar parecer técnico, fiscalizar e cobrar dos gestores municipais as adequações. Da mesma forma, o CAE tem papel importante na fiscalização destes espaços e no acompanhamento de ações que busquem melhorar as condições físico-sanitárias das UAN [18].
Almeida et al. [36], em pesquisa realizada com 296 UAN escolares, encontraram inadequações em todas as unidades, sendo mais frequentes aquelas relacionadas à estrutura física e instalações. A responsabilidade pela estrutura física das unidades escolares é da chamada Entidade Executora, ou seja, prefeituras e estado. O recurso enviado pelo FNDE para a alimentação escolar é destinado apenas à aquisição de gêneros alimentícios e, conforme detalhado na legislação, tem caráter suplementar ${ }^{[18]}$.

A ausência de instrumentos de exibilidade quanto à adequação das UAN escolares por parte das entidades executoras é um aspecto que pode comprometer a qualidade da alimentação ofertada, assim como ferir os princípios da SAN e do DHAA no ambiente escolar. $\mathrm{O}$ estabelecimento de uma normatização específica quanto as responsabilidades da entidade executora, incluindo a garantia de estrutura física adequada e de recursos humanos compatíveis com a execução dos cardápios e exigências do programa, a complementação financeira ao recurso enviado pelo FNDE, dentre outros aspectos, pode constituir um importante caminho para superar este entrave. É comum que gestores municipais ou estaduais do PNAE compreendam a execução deste apenas pela vertente de processos de compras em conformidade com a lei, desconsiderando a estrutura das UAN e os profissionais responsáveis pela manipulação de alimentos como elementos fundamentais.

Considerando a limitação de atuação da equipe sobre estas questões foram realizadas ações de sensibilização dos gestores municipais da educação no tocante as UAN escolares.

\section{Desconhecimento do processo de compra}

Foi uma queixa frequente dos profissionais vinculados ao setor educação a questão dos preços praticados pelos agricultores familiares, que em alguns casos, eram superiores àqueles encontrados nos mercados locais. Triches e Schneider [9,15] analisando a mesma temática destacam o fato dos mercados varejistas apresentarem melhor preço pela aquisição em maior quantidade e, no caso dos agricultores o preço é influenciado pela pequena escala de produção. Um avanço neste processo decorre da publicação da Resolução CD/FNDE no 26/2013 [18] e a manutenção pela Resolução CD/FNDE no 4/2015 [19] que determinam o estabelecimento de um preço de 
aquisição determinado por pesquisa local e divulgado pela Secretaria de Educação.

Outra dificuldade refere-se à resistência de técnicos dos setores de compras na execução de chamadas públicas. Estes alegavam maior segurança no processo de compra junto a mercados varejistas, tendo em vista a relação comercial já consolidada. Ações de formação e incentivo por meio de articulação com representantes da agricultura familiar no município podem ser implantadas buscando diminuir esta resistência.

\section{Descumprimento das chamadas públicas}

As chamadas públicas analisadas pelo projeto não descreviam o cronograma de entrega; as responsabilidades e penalidades do contratante (prefeitura), local de entrega e informações sobre preço de referência para a aquisição dos alimentos.

A ausência de uma atuação integrada entre a prefeitura e outras instituições (organizações de agricultores familiares, entidades religiosas, associações de bairros, e outros) dificulta a divulgação das chamadas públicas. Neste estudo formações sobre chamada pública fizeram com que alguns municípios inserissem o local de entrega, as quantidades a serem adquiridas e o preço de aquisição dos alimentos.

A publicação das chamadas em períodos e frequências variáveis, não permite que agricultores e técnicos planejem a produção e organizem a documentação. Esse desafio foi solucionado em um dos municípios do TVP por meio de acordo entre a direção da cooperativa local, a gestão do PNAE e o departamento de compras do município, fixando o mês de publicação das chamadas públicas. Em outro município do TVRV, na impossibilidade da prefeitura em fixar datas para publicação das chamadas, a gestão da educação se comprometeu a avisar os agricultores com antecedência.

Em relação à divulgação, foi observado que nos municípios em que os técnicos da Emater-Goiás e os secretários de agricultura foram os responsáveis pela divulgação, os resultados foram mais efetivos e mais agricultores se interessaram. Explica-se este resultado pela relação de confiança entre estes atores sociais, atuando como uma garantia de efetivação da compra e atendimento dos direitos dos agricultores familiares.

\section{Atuação, ainda parcial, dos Conselhos de Alimentação Escolar}

Apesar de um percentual significativo dos CAEs dos Territórios da Cidadania atuarem de forma articulada com a agricultura familiar e acompanharem a execução do PNAE, a presença de agricultores como conselheiros é ainda pequena. Em ambos os territórios, foi inevitável a constatação de que muitos conselheiros são assim designados fundamentalmente para cumprir com a exigência da legislação e validar os pareceres das prestações de contas das entidades executoras. Isso demonstra quão importante é a população entender a relevância dos conselhos na fiscalização $e$ acompanhamento dos gastos dos recursos públicos $[2,18]$.

Análise dos dados do Prêmio Gestor Eficiente da Merenda Escolar indica que um fator determinante e diferenciador das unidades executoras vencedoras foi a participação social. Um CAE considerado ativo em buscar melhorias à execução do PNAE, tende a alcançá-las de forma mais promissora [11]. Nos municípios em que havia o CAE atuante, a participação dos conselheiros na elaboração dos planos de ação para superação dos entraves foi um diferencial para proposição de estratégias mais assertivas e coerentes com a realidade local.

\section{Reflexões sob a ótica agrícola/agrária}

A ausência de apoio local à agricultura familiar impacta diretamente na comercialização com a alimentação escolar. A seguir são elencados entraves que compõe este grupo de reflexões.

\section{Precarização da Assistência Técnica e Extensão Rural}

Em todos os municípios estudados foi identificada a presença de, pelo menos, um técnico da Emater-Goiás. No entanto, foi comum a queixa de agricultores quanto à dificuldade de acessar informações sobre os mercados institucionais. Os técnicos de ATER foram citados como importantes no mapeamento dos agricultores, no auxílio à organização da produção, principalmente em relação ao escalonamento [37]. 
No presente projeto, foi relatado que a aproximação entre o órgão responsável pela ATER no município e os agricultores familiares tornou o processo de organização dos documentos e do projeto de venda menos complexo para estes últimos.

\section{Baixa diversificação da produção}

A oferta de alimentos ao PNAE deve ser diversificada, buscando assim atender às necessidades nutricionais dos escolares ${ }^{[2,18]}$. Em municípios menores a compra ocorre em pequenos volumes, exigindo assim que o agricultor familiar diversifique seus cultivos, a fim de que o volume de venda seja economicamente atrativo. A baixa diversidade produtiva foi justificada pela atratividade econômica de algumas culturas, a ausência de outros mercados para comercialização e a insegurança de produzir alimentos sem ATER. Nesse caso, a gestão da agricultura pode apoiar os agricultores abrindo outros mercados como o Programa de Aquisição de Alimentos (PAA), potencializando as condições para a execução do PNAE [38].

Em um dos municípios do TVRV, os agricultores alegaram que não produziam com maior diversidade, pois não tinham mercado para alguns produtos. Nos municípios em que o nutricionista foi orientado a elaborar uma lista de alimentos da alimentação escolar, os resultados foram positivos. Com a garantia da gestão da educação na compra desses alimentos e o incentivo da secretaria de agricultura por meio de ATER, os agricultores mostraram interesse em diversificar a produção para conseguir aumentar o quantitativo de venda.

\section{Desarticulação entre a gestão municipal e a agricultura familiar}

Os gestores da agricultura dos municípios deste estudo relataram a disponibilização de maquinário como estratégia da ATER para a agricultura familiar. Em um município do TVRV em que o Conselho Municipal de Desenvolvimento Rural e Sustentável é mais atuante, a Câmara Municipal, após várias audiências públicas, aprovou uma lei municipal específica para o desenvolvimento da agricultura familiar do município. Em outro município do TVRV, a estratégia adotada para fortalecer os agricultores familiares foi a feira local, que oportunizou um aumento da renda e do recolhimento financeiro pela cooperativa, passando esta a contratar ATER aos cooperados. A feira foi utilizada tanto como um incentivo à organização produtiva, uma vez que a oferta de alimentos aos consumidores passou a ser semanal, como incentivou os agricultores a diversificar a sua produção.

\section{Acesso à Declaração de Aptidão ao Pronaf (DAP)}

Principalmente nos assentamentos de reforma agrária os relatos de problemas com a documentação da terra foram recorrentes. Isso dificulta o acesso a DAP e a regularização fundiária, impossibilitando a venda para o PNAE. A estratégia de superação deste entrave é mais complexa, uma vez que depende de uma articulação com as unidades regionais do Instituto Nacional de Colonização e Reforma Agrária.

\section{Ausência ou baixa organização dos agricultores familiares}

Dos municípios participantes deste estudo, 10 apresentavam cooperativas formadas somente ou predominantemente por agricultores familiares. A organização dos produtores em cooperativas é vista como uma ação fundamental para a efetivação da compra pelo PNAE.

Percebe-se que a organização dos agricultores, mesmo que em associações ou em grupos não formalizados, agregam maior poder de negociação, promove a redução nos custos de logística e consequentemente tornam estes mais competitivos no mercado devido ao maior volume de produção ofertado. Os agricultores organizados tendem ainda a procurar diversificação de mercados, incluindo nestes os institucionais [37].

No entanto, inúmeros são os desafios das organizações locais, sendo comum cooperativas que foram constituídas com o único objetivo de facilitar a comercialização. As cooperativas não possuem identidade, as direções são centralizadas em poucos líderes e há muitos problemas de gestão administrativa e de recursos.

Uma solução encontrada para uma cooperativa no TVRV foi o estabelecimento de parceria com a Universidade Federal de Goiás para a execução de uma ação de extensão em 2013. Na execução, os técnicos e estudantes atuam junto à cooperativa nas ações de organização da produção dos agricultores, 
passando pela gestão e chegando até a comercialização de seus produtos com abertura e garantia de diversos mercados [39].

\section{Acesso à regularização sanitária dos alimentos}

Além da falta de recursos e de estudos sobre a viabilidade financeira e econômica da construção de uma agroindústria familiar, os agricultores esbarram na dificuldade em conseguir a regularização ambiental, tributária e sanitária. Para agroindústrias a maior dificuldade é a captação de recursos para construir estruturas adequadas e para a manutenção do funcionamento.

Uma instância local que pode contribuir para diminuir este entrave é o Serviço de Inspeção Municipal (SIM). O SIM estava em funcionamento em apenas um município do TVP, já no TVRV, dos 15 municípios participantes deste estudo, apenas um possuía o SIM aprovado, porém ainda não implantado. A publicação do Decreto no 8.445, de 6 de maio de $2015{ }^{[40]}$ que trata do Sistema Unificado de Atenção à Sanidade Agropecuária (SUASA) foi considerado um indício de superação deste desafio. O SUASA subordina os municípios à inspeção estadual, tornando mais concreta a necessidade de uma atuação integrada entre estas duas esferas de gestão. Corrobora com isso uma das orientações transmitidas aos municípios pela equipe deste projeto, de incentivo à organização de consórcios de municípios para a implantação do SIM. Esta ação além de reduzir os custos com infraestrutura e técnicos, viabiliza a comercialização dos produtos em todos os municípios consorciados.

\section{CONCLUSÕES}

Os municípios que compõem os dois Territórios da Cidadania estudados possuem potencial econômico e social cujo alcance depende da participação e empoderamento dos atores das políticas públicas. O presente estudo demonstra que ações executadas de forma intersetorial e integrada tendem a favorecer o alcance de objetivos de políticas públicas.

A proximidade com a realidade local favoreceu uma melhor compreensão sobre os pontos centrais para o cumprimento efetivo da legislação do PNAE, sendo marcante a influência que as mudanças na gestão local tenderam a exercer sobre os processos em curso. $\mathrm{O}$ enfraquecimento de dinâmicas locais imposto pelos processos de descontinuidade administrativa no decorrer deste projeto influenciou a execução da Lei no 11.947/2009 e, consequentemente, os resultados finais do estudo. Os resultados também contribuem para ressaltar as limitações de ordem política, institucional e agrária/agrícolas que interferem diretamente no cumprimento das ações previstas pelo PNAE. A superação destas parece ser um entrave maior, no qual os diferentes níveis de gestão pública devem atuar.

Este estudo apresenta algumas limitações como o pequeno tamanho da amostra para realização de testes de associação, a não continuidade no acompanhamento dos municípios e a utilização do telefone como fonte de coleta de informações. Buscando reduzir esta última limitação, foram adotadas diversificadas fontes de informações, alcançando resultados mais fidedignos com a realidade, assim como o apontamento de questões a serem aprofundadas no campo de estudo sobre as políticas públicas e, especialmente, sobre o PNAE.

Por fim, destaca-se que a experiência da parceria do FNDE com as Instituições Públicas de Ensino Superior, expressas pelos CECANEs, deve ser fortalecida. A atuação dos CECANEs em parceria com as gestões locais do PNAE tende a fortalecer e ampliar a abrangência desta política pública.

\section{AGRADECIMENTOS}

Ao FNDE pelo financiamento. A Amanda Oliveira, Bruna Bittar, Flaviana Oliveira, Maria Amélia Falqueto, Marcos Vinícius Santos, Natália Barbosa, Rodolfo Barreto, Suzana, Profa Maria do Rosário G. Peixoto e a todos(as) agricultores(as) familiares, nutricionistas e gestores(as).

\section{REFERÊNCIAS}

[1] Peixinho AML. A trajetória do Programa Nacional de Alimentação Escolar no período de 2003-2010: relato do gestor nacional. Ciênc. Saúde Coletiva. 2013;18(4):909-916.

[2] Brasil. Lei no 11.947, de 16 de junho de 2009. Dispõe sobre o atendimento da alimentação escolar e do Programa Dinheiro Direto na Escola aos alunos da educação básica. Diário Oficial da União. 17 jun 2009. 
[3] Sidaner E, Balaban D, Burlandy L. The Brazilian school feeding programme: an example of an integrated programme in support of food and nutrition security. Public Health Nutrition. 2013;16(6):989-994.

[4] Schneider S, Shiki S, Belik W. Rural development in Brazil: overcoming inequalities and building new markets. Rev. Econ. Agr. 2010;65(2):225-259.

[5] Rocha C, Burlandy L, Maluf R. Small farms and sustainable rural development for food security: The Brazilian experience. Dev. So. Afr. 2012;29(4):519-529.

[6] Turpin ME. A alimentação escolar como fator de desenvolvimento local por meio do apoio aos agricultores familiares. Segur. Aliment. Nutr. 2009;16(2):20-42.

[7] Centro de Estudos do Trabalho e de Assessoria ao Trabalhador - CETRA. Políticas Públicas e transição agroecológica no Brasil: reflexões a partir de estudos de caso [internet]. Recife; 2014. [acesso em 10 maio 2015]. Disponível em: http://www.cetra.org.br/cartilha/148-politicas-publicas-etransicao-agroecologica-no-brasil

[8] Teo CRPA, Monteiro CA. Marco legal do Programa Nacional de Alimentação Escolar: uma releitura para alinhar propósitos e prática na aquisição de alimentos. Rev. Nutr. 2012;25(5):657-668.

[9] Triches RM, Schneider S. Alimentação escolar e agricultura familiar: reconectando o consumo à produção. Saúde Socied. 2010;19(4):933-945.

[10] Saraiva EB, Da Silva APF, De Sousa AA, Cerqueira GF, Chagas CMS, Toral N. Panorama da compra de alimentos da agricultura familiar para o Programa Nacional de Alimentação Escolar. Ciênc. Saúde Coletiva. 2013;18(4):927-935.

[11] Belik W, Chaim NA. O programa nacional de alimentação escolar e a gestão municipal: eficiência administrativa, controle social e desenvolvimento local. Rev. Nutr. 2009;22(5):595-607.

[12] Monego ET, Alexandre VP, Sousa LM, Martins KA, Rosa JQS, De Sousa PLC, et al. Produção e potencial agrícolas de alimentos destinados à alimentação escolar em Goiás e no Distrito Federal, na Região Centro-oeste do Brasil. Rev. Nutr. 2013;26(2):233-241.

[13] Triches RM, Schneider S. Desestruturar para construir: interfaces para a agricultura familiar acessar o programa de alimentação escolar. Rev. Estudos Socied. Agric. 2013;20(1):66105.

[14] Maluf RSJ. Segurança alimentar e nutricional. Petrópolis: Vozes; 2007.
[15] Triches RM, Schneider S. Reconstruindo o “elo perdido”: a reconexão da produção e do consumo de alimentos através do Programa de Alimentação Escolar no município de Dois Irmãos (RS). Segur. Aliment. Nutr. 2010;17(1):1-15.

[16] Brasil. Portal da Cidadania. Territórios da Cidadania [internet]. Brasília (DF); 2012 [acesso em 10 dez 2012]. Disponível em: http://www.territoriosdacidadania.gov.br

[17] Brasil. Resolução no 38, de 16 de julho de 2009. Dispõe sobre o atendimento da alimentação escolar aos alunos da educação básica no âmbito do Programa Nacional de Alimentação Escolar - PNAE [internet]. [acesso em 15 jan 2012]. Disponível em: http://www.fnde.gov.br/fnde/legislacao/resolucoes/item/462 0 -resolu $\% \mathrm{C} 3 \% \mathrm{~A} 7 \% \mathrm{C} 3 \% \mathrm{~A} 3 \mathrm{o}-\mathrm{cd}-$ fnde-n $\% \mathrm{C} 2 \% \mathrm{BA}-26$,-de- 17 de-junho-de-2013

[18] Brasil. Resolução no 26, de 17 de junho de 2013. Dispõe sobre o atendimento da alimentação escolar aos alunos da educação básica no âmbito do Programa Nacional de Alimentação Escolar - PNAE [internet]. [acesso em 09 out 2013]. Disponível em: http://www.fnde.gov.br/fnde/legislacao

[19] Brasil. Resolução no 4, de 2 de abril de 2015. Altera a redação dos artigos 25 a 32 da Resolução/CD/FNDE no 26, de 17 de junho de 2013, no âmbito do Programa Nacional de Alimentação Escolar (PNAE) [internet]. [acesso em 15 maio 2015]. Disponível em: http://www.fnde.gov.br/fnde/legislacao

[20] Freire P. Pedagogia do Oprimido. 50ed. Rio de Janeiro: Paz e Terra; 2011.

[21] Alexandre VP, Almeida KM, Rosa JQS, Monego ET, Oliveira RKA, Menezes IHCF, et al. Agricultura familiar: do campo à mesa do escolar. Goiânia: Índice Gestão Editorial; 2010.

[22] Minayo MCS, Deslanes SF. Pesquisa social: Teoria, método e criatividade. 22ed. Petrópolis: Vozes; 2003.

[23] Brasil. Ministério do Desenvolvimento Agrário. Declaração de Aptidão ao PRONAF [internet]. Brasília (DF); 2012 [acesso em 12 jan 2012]. Disponível em: http:/ / comunidades.mda.gov.br

[24] Instituto Brasileiro de Geografia e Estatística. Cidades@2010 [internet]. Rio de Janeiro; 2013. [acesso em 05 mar 2012]. Disponível em: http://www.ibge.gov.br/cidadesat

[25] Brasil. Ministério do Desenvolvimento Agrário. Valor do repasse FNDE por estado e município - 2011 [internet]. Brasília (DF); 2011. [acesso em 18 jan de 2012]. Disponível em: http://www.mda.gov.br 
[26] Instituto Nacional de Estudos e Pesquisas Educacionais Anísio Teixeira. Índice de Desenvolvimento da Educação Básica - Resultados e metas [internet]. Brasília (DF); 2011. [acesso em 01 fev de 2012]. Disponível em: http://ideb.inep.gov.br

[27] Bezerra OMPA, Bonomo E, Silva CAM, Correa MS, Souza AA, Santos PCT, et al. Promoção da aquisição de produtos da agricultura familiar para a alimentação escolar em Territórios da Cidadania de Minas Gerais e Espírito Santo. Rev. Nutr. 2013;26(3):335-342.

[28] Carvalho DG. Licitações sustentáveis, alimentação escolar e desenvolvimento Regional: uma discussão sobre o poder de compra governamental a favor da sustentabilidade. Planej. Políticas Publ. 2009;32:115-148.

[29] Chaves LG, Mendes PNR, Brito RR, Botelho RBA. O Programa Nacional de Alimentação Escolar como promotor de hábitos alimentares regionais. Rev. Nutr. 2009;22(6):857-866.

[30] Brasil. Conselho Federal de Nutricionistas - CFN. Resolução no 465, de 23 de agosto de 2010. Dispõe sobre as atribuições do Nutricionista, estabelece parâmetros numéricos mínimos de referência no âmbito do Programa de Alimentação Escolar (PAE) e dá outras providências. Diário Oficial da União. 25 out 2010; Seção 1:118-119.

[31] Triches RM, Gerhardt TE, Schneider S. Políticas alimentares: interações entre saúde, consumo e produção de alimentos. Interações. 2014;15(1):109-120.

[32] Cazella AA, Bonnal P, Maluf RS. Multifuncionalidade da agricultura familiar no Brasil e o enfoque da pesquisa. In: Cazella AA, Bonnal P, Maluf RS. Agricultura familiar: multifuncionalidade e desenvolvimento territorial no Brasil. Rio de Janeiro: Mauad X; 2009.

[33] Paulillo LF. Sobre o Desenvolvimento da Agricultura Brasileira: Concepções Clássicas e Recentes. In: Batalha MO. Gestão Agroindustrial. Grupo de Estudos e Pesquisas Agroindustriais. 3ed. São Paulo: Atlas, 1997.
[34] Oliveira A. Burocratas da linha de frente: executores e fazedores das políticas públicas. Rev. Adm Públ. 2012;46(6):1551-1573.

[35] Real LCV, Schneider S. O uso de programas públicos de alimentação na reaproximação do pequeno produtor com o consumidor: o caso do programa de alimentação escolar. Estudo Debate. 2011;18(2):57-79.

[36] Almeida KM, André MCP, Campos MRH, Díaz MEP. Hygienic, sanitary, physical, and functional conditions of Brazilian public school food services. Rev. Nutr. 2014;27(3):343356.

[37] Corrêa ES, Silva LX, Agne CL. Programa nacional de alimentação escolar: um canal de comercialização da agricultura familiar em São Lourenço do Sul. In: 51ํ Congresso da Sociedade Brasileira de Economia, Administração e Sociologia Rural: novas fronteiras da agropecuária no Brasil e na Amazônia - desafios da sustentabilidade; 21-24 jul 2013; Belém - PA. 2013.

[38] Becker C, Andersson FS, Altemburg SGN, Costa LC. Novas concertações sociais e antigos entraves "burocráticos": a produção de base familiar e ecológica frente aos desafios de acesso ao PNAE. Cad. Agroecol. 2011;6(2):2-5.

[39] Alexandre VP, Martins BB, Harold CAS. Construindo novas trajetórias e fortalecendo redes por meio de desenvolvimento rural sustentável - FANUT 133. Relatório final. Goiânia: Universidade Federal de Goiás; 2014.

[40] Brasil. Decreto no 8.445, de 06 de maio de 2015. Altera o Anexo ao Decreto no 5.741, de 30 de março de 2006, que regulamenta os arts. 27-A, 28-A e 29-A da Lei no 8.171, de 17 de janeiro de 1991, e organiza o Sistema Unificado de Atenção à Sanidade Agropecuária. Diário Oficial da União. 07 mai 2015. 